\title{
O DIREITO PELOS OLHARES DE PALOMAR
}

\author{
ISABEl CRistina BRetTas DUARTE ${ }^{1}$ \\ ANgelita MARIA MADERS ${ }^{2}$
}

\begin{abstract}
RESUMO: Neste artigo são trazidas algumas inquietações acerca do universo jurídico e da necessidade de sua maior aproximação com a Literatura. Para isso, parte do pressuposto de que o Direito é linguagem e criação humana e que, para melhor compreendê-lo, deve haver uma interface com a ficção. Inicia com uma incursão sobre o livro Palomar, de Ítalo Calvino, mais especificamente com a terceira parte da obra, "O silêncio de Palomar" e "As viagens de Palomar", para depois, aventurar-se na Teoria Poética do Direito, para o que se utiliza como pano de fundo o livro A teoria poética do direito de Willis Santiago Guerra Filho. Tem como objetivo principal analisar a aplicação da referida teoria em Palomar, buscando contemplar as diferentes lentes com que se pode exercer a atividade do olhar, do perceber, do posicionar-se em diferentes ângulos para buscar a visão do todo - embora a compreensão da impossibilidade de sua apreensão, especialmente na seara jurídica -, numa perspectiva de transformação do paradigma da filosofia da consciência para o da filosofia da linguagem. A pesquisa realizada, em relação ao objetivo, é dialética; e quanto ao método utilizado, fenomenológicohermenêutico, por meio de uma abordagem dedutiva e bibliográfica.
\end{abstract}

Palavras-chave: direito; literatura; teoria poética do direito; Palomar.

1 Advogada da Procuradoria-Geral do Município de Santo Ângelo. Doutoranda em Direito pela Universidade Regional Integrada do Alto Uruguai e das Missões (URI). Mestre em Direito (URI). Mestre em Letras (URI). Santo Ângelo (RS). CV Lattes: http://lattes.cnpq.br/2327203177156787. E-mail: isabelcristinabd@yahoo.com.br.

2 Defensora Pública do Estado na Comarca de Santo Ângelo/RS, Professora do Programa de Pós-Graduação em Direito da Universidade Regional Integrada do Alto Uruguai e das Missões (URI). Mestre em Gestão, Desenvolvimento e Cidadania pela Universidade Regional do Noroeste do Estado do Rio Grande do Sul (Unijuí). Doutora em Direito pela Universität Osnabrück (Alemanha). Pós-doutorado na Universidad de Santiago do Chile. Membro do Núcleo de Direitos Humanos da Defensoria Pública do Estado do Rio Grande do Sul, Brasil. Santo Ângelo (RS). CV Lattes: http://lattes.cnpq.br/0351058884981619. E-mail: angmaders@hotmail.com. 
Minha confiança no futuro da Literatura consiste em saber que há coisas que só a Literatura com seus meios específicos nos pode dar, [...] alguns valores ou qualidades ou especificidades da Literatura que me são particularmente caros. (Ítalo Calvino)

\section{CONSIDERAÇÕES INICIAIS}

Este texto está permeado de inquietações típicas do observador, daquele que enxerga, mas, muitas vezes, não pode ou não consegue, com palavras, expressar a amplitude de tudo o que vê, o que sente e o que imagina devesse ser dito, revisto ou olvidado. Ele parte do pressuposto de que o Direito é uma criação humana e que é necessária uma compreensão do universo jurídico em aproximação com o da ficção e, mais especificamente, com a Literatura, a exemplo do que vêm propondo diversos jusfilósofos de renome internacional, como é o caso de Ronald Dworkin e Martha Nussbaum.

Dentre o conjunto de teses já defendidas sobre o tema, duas são as matrizes teóricas que foram escolhidas para embasar o estudo proposto no presente artigo: a Teoria Poética do Direito, fruto da tese de doutorado do professor Willis Santiago Guerra Filho, e o livro Palomar, de Ítalo Calvino.

Pretende-se, assim, analisar Palomar a partir da Teoria poética do direito, de modo a contemplar as diferentes lentes com que se pode exercer a atividade do olhar, do perceber, do posicionar-se em diferentes ângulos para buscar a visão do todo, apesar da compreensão da impossibilidade de sua apreensão.

Também é abordada a passagem do paradigma da filosofia da consciência para o da filosofia da linguagem, bem como os três modelos de juiz elaborados por François Ost, como forma de embasamento das análises propostas da obra e dos personagens.

A pesquisa realizada, em relação ao objetivo, é dialética; e o método utilizado, fenomenológico-hermenêutico, por meio de uma abordagem dedutiva e bibliográfica.

\section{POR QUE PALOMAR?}

A eleição da obra Palomar como pano de fundo para este artigo devese ao próprio significado de seu título, que, se acredita, tem o condão de 
representar o que se pretende transmitir com as observações que serão pontuadas neste texto acerca de um tema que, em um primeiro momento, parece ser-lhe distante. Mas, para melhor compreender o que foi dito, ou melhor, escrito até agora, nesse intuito introdutório, é preciso esclarecer: a escolha de Ítalo Calvino para o título daquele que foi o seu último livro publicado em vida é digna de análise. Palomar é o nome de um famoso observatório astronômico que, durante muito tempo, ostentou o maior telescópio do mundo, conforme informação que consta na apresentação do livro. E, assim, funciona Palomar como um telescópio ao contrário, voltado para as coisas próximas e não para a amplidão, mas, em aparente paradoxo, justamente buscando a compreensão da amplidão do universo.

Já nas primeiras páginas do livro, Palomar está a observar uma onda, ou em dúvida sobre pousar ou não seu olhar sobre o seio nu de uma banhista, ou a praticar sua natação vespertina a confrontá-lo com a espada do sol, ou no jardim, a observar os amores das tartarugas... Tudo para ele é objeto de estudo, de curiosidade, de espanto, de perguntas, de dúvidas, o que, aliás, é uma constante na vida do observador, daquele que tem como profissão observar e, portanto, está sempre a trabalhar, mesmo quando está a descansar.

O árduo trabalho de Palomar está retratado em diversos capítulos da obra de Calvino, nos quais afloram as vastas qualidades literárias do autor, que o tornaram mundialmente conhecido e reconhecido. Contudo, diante da impossibilidade de se abordar todos os títulos do índice e para não perder de vista o objetivo proposto neste estudo, com a devida vênia ao próprio autor e também ao leitor, concentra-se a análise no terceiro título: "Os silêncios de Palomar".

Dentre "Os silêncios de Palomar", destacam-se “As viagens de Palomar"; afinal, "a viagem é um dos arquétipos temáticos e simbólicos dentre os mais produtivos da Literatura. Sempre renovável, oferece à literatura uma de suas grandes matérias-primas" (Bernd, 2007, p. 675). De fato, considerando o mundo multicultural em que se vive, a viagem é um operador cognitivo e simbólico das trocas semânticas e da multiplicação dos signos que produz o narrador, assim como o faz Palomar.

Desse modo, inicia-se mais especificamente com "Serpentes e caveiras". Trata-se de uma viagem às ruínas de Tula, no México: 
No México o senhor Palomar está visitando as ruínas de Tula, antiga capital dos toltecas. Acompanha-o um amigo mexicano, conhecedor apaixonado e eloquente das civilizações pré-hispânicas, que lhe conta belíssimas lendas sobre Quetzalcóatl. [...] $\mathrm{Na}$ arqueologia mexicana cada estátua, cada objeto, cada detalhe de baixo relevo significa alguma coisa que significa alguma coisa que por sua vez significa alguma coisa. Um animal significa um deus que significa uma estrela que significa um elemento ou uma qualidade humana, e assim por diante. Estamos no mundo da escrita pictográfica; para escrever, os antigos mexicanos desenhavam figuras, e mesmo quando desenhavam figuras era como se escrevessem: cada figura se apresenta como um rébus a ser decifrado. Mesmo os frisos mais abstratos e geométricos numa parede do templo podem ser interpretados como setas se apresentam um motivo de linhas pontilhadas, ou neles podemos ler uma sucessão numérica segundo a maneira como se desenvolvem as gregas. Aqui em Tula os baixosrelevos repetem figuras animais estilizadas: jaguares, coiotes (Calvino, 1994, p. 88-89).

Contrapondo-se à figura do amigo de Palomar, que vai desenvolvendo teorias que explicam o porquê de tudo - "O amigo mexicano detém-se diante de cada pedra, transforma-a em narrativa cósmica, em alegoria, em reflexão moral" (Calvino, 1994, p. 89) -, está o professor que guia um grupo de estudantes, cujas falas eram entreouvidas por Palomar enquanto escutava as explicações de seu amigo mexicano que o guiava.

Acerca desses três personagens, Palomar, o amigo mexicano e o professor, é possível estabelecer uma conexão com o texto "Júpiter, Hércules, Hermes: tres modelos de juez”, publicado originalmente na Revista Doxa em 1993, relacionando três modelos de juiz com as características mitológicas dos deuses Júpiter, Hércules e Hermes, os quais representariam diferentes paradigmas jurídicos. Júpiter está no topo de uma pirâmide e seu olhar se dá a partir de um local sagrado, aplicando as leis e os códigos, enquanto Hércules constrói o direito a partir da decisão. Já Hermes representa um novo modelo, cujas combinações não cabem em códigos ou decisões (Ost, 2007).

O primeiro modelo, legalista e burocrático, não exerce a criatividade e nem se preocupa com transformações. O segundo modelo, atento ao cotidiano, busca transformar a generalidade e abstração da lei, visando à apreensão do sentido de um caso concreto, enquanto o terceiro modelo, sabedor da multidimensionalidade do direito, preocupa-se com as 
constantes transformações e os diversos sentidos advindos de realidades intangíveis que lhe sucedem.

Assim, as posturas dos três personagens, extraídas das características observadas no texto, revelam esses três modelos trazidos por Ost: o professor pode ser associado a Júpiter, Palomar a Hércules e o amigo mexicano a Hermes. Tais posturas revelam-se em alguns trechos do texto, conforme explanado na sequência.

Então, Palomar começou a observar que, depois de fornecer alguns dados factuais acerca do lugar, das estátuas e das figuras, o professor concluía com "não se sabe o que querem dizer". Acerca dessa postura radicalmente oposta àquela do guia, tem-se a atitude de Palomar:

Fica fascinado pela riqueza de referências mitológicas do amigo: o jogo das interpretações, a leitura alegórica sempre lhe pareceram um exercício soberano da mente. Mas sente-se atraído também pelo comportamento oposto do professor da escola: aquilo que lhe pareceu a princípio uma expedita falta de interesse aos poucos vai se revelando a ele como uma postura científica e pedagógica, uma escolha de método daquele jovem grave e consciencioso, uma regra a que não quer renunciar. Uma pedra, uma figura, um signo, uma palavra que nos cheguem isolados do seu contexto são apenas aquela pedra, aquela figura, aquele signo ou palavra: podemos tentar defini-los, descrevê-los como tais, só isto; se além da face que nos apresentam, possuem também uma outra face, a nós não é dado sabê-lo. A recusa em compreender mais do que aquilo que estas pedras mostram é talvez o único modo possível de demonstrar respeito por seu segredo; tentar adivinhar é presunção, traição do verdadeiro significado perdido (Calvino, 1994, p. 89-90).

Portanto, como num rito de passagem representando um viés intermediário, a postura investigativa e observadora de Palomar depara-se com o contraponto do professor, cuja leitura legalista não lhe permitia ver nada além do que estava posto e do amigo mexicano, cuja leitura lúdica permitia-lhe ver tudo aquilo que pode ser captado pelas lentes da criatividade, criando sentidos inexistentes para o professor.

Tanto é assim que, quando chegam ao Muro das Serpentes, ocorre o ponto alto da narrativa:

Passam os estudantes. E o professor: "Este é o Muro das Serpentes. Cada serpente tem uma caveira na boca. Não se sabe o que significam". O amigo não consegue conterse: "Claro que se sabe! É a continuidade da vida e da morte, as serpentes são a vida, as caveiras são a morte; a vida que é vida porque traz consigo a morte e a morte que 
é morte porque sem morte não há vida...” (Calvino, 1994, p. 90).

Nesse ponto alto, culminam as reações dos envolvidos, bem como as reflexões de Palomar:

Os rapazotes ficam a ouvir de boca aberta, os olhos negros atônitos. $\mathrm{O}$ senhor Palomar pensa que toda tradução requer uma outra tradução, e assim por diante. Pergunta-se a si mesmo: "Que queria dizer morte, vida, continuidade, passagem para os antigos toltecas... E que poderá querer dizer para esses garotos... E para mim..." Contudo, sabe que não poderia jamais sufocar em si a necessidade de traduzir, de passar de uma linguagem a outra, de uma figura concreta a palavras abstratas, de símbolos abstratos a experiências concretas, de tecer e tornar a tecer uma rede de analogias. Não interpretar é impossível, como é impossível abster-se de pensar. Mal o bando de estudantes desaparece numa curva, a voz obstinada do pequeno professor continua: "No es verdad, não é verdade o que aquele señor disse. Não se sabe o que significam" (Calvino, 1994, p. 90).

Do exposto nessas reflexões, percebe-se que não sem razão é a escolha do nome para o livro. De fato, como um telescópio ao contrário, voltado para as coisas próximas e aparentemente simples, Palomar busca compreender a amplidão do todo, envolta em toda a sua complexidade. Nessa busca, "Palomar se apropria do mundo pelo olhar, um espaço pleno de representação onde ele se inscreve enquanto olha” (Hellmann, 2010, p. $58)$.

Tal apropriação do mundo e os novos olhares que resultam desse processo de observação trazem como consequência o embate de ideias, que obriga a desviar do olhar comum, a sair da zona de conforto, do que Palomar revela-se ciente, segundo o narrador:

O fato é que mais do que afirmar sua verdade ele gostaria
de fazer perguntas, e compreender que ninguém está
disposto a sair dos trilhos de seu próprio discurso para
responder a perguntas que, vindas de um outro discurso,
obrigariam a repensar as mesmas coisas com outras
palavras, e quem sabe encontrar-se em território
desconhecido, diante dos percursos seguros (Calvino,
1994, p. 95).

$\mathrm{Na}$ busca por respostas, encontram-se os olhares de quem observa e de quem é observado: Palomar, o amigo mexicano e o professor, cada qual com sua visão de mundo, seus condicionantes culturais, suas idiossincrasias, sua formação pessoal: 
Mas como é possível observar alguma coisa deixando à parte o eu... De quem são os olhos que olham... [...] Logo, não basta que Palomar observe as coisas por fora e não por dentro: daqui por diante irá observá-las com um olhar que vem do exterior, não de dentro de si mesmo Procura fazer a experiência: agora não é ele que está olhando, mas é o mundo exterior que olha para fora. Isto estabelecido, gira o olhar em torno à espera de uma transfiguração geral. Mas qual! É a costumeira mesmice cotidiana que o circunda. Precisa reestudar tudo desde o princípio. Não basta que seja o exterior que esteja observando o exterior: é da coisa observada que deve partir a trajetória que a associa à coisa que observa (Calvino, 1994, p. 102).

Pelos trechos anteriormente citados, percebe-se que Palomar, em sua aguçada curiosidade, não se contenta com respostas simples, problematizando os objetos de sua observação na busca por respostas complexas, justamente porque compreende a complexidade do mundo expressa em todas as coisas, por mais simples que possam parecer num primeiro olhar desavisado. Tais respostas complexas a questões complexas passam pela criatividade, responsável pela postura inovadora do amigo mexicano de Palomar, e demandam algumas digressões também sobre os diferentes paradigmas filosóficos que emergem a partir da análise proposta.

Nessa senda, uma mudança paradigmática pode ser percebida também na relação entre os modelos anteriormente referidos e a transição da filosofia da consciência ou do sujeito para a filosofia da linguagem, com influências tanto no Direito quanto na Literatura. Enquanto na primeira prevalece a relação sujeito-objeto, mais especificamente a ação do sujeito sobre o objeto, privilegiando uma única linguagem, aquela do racionalismo, da ciência em seu modelo cartesiano, no qual há um conhecimento verdadeiro traduzido em teorias interpretativas da realidade; na segunda, a linguagem é posta como questão central, enquanto constituinte do mundo, a partir dos sentidos que são dados às coisas, aos significantes e significados.

Embora seja digno de outra escrita mais aprofundada, não se pode deixar de mencionar que essa ruptura paradigmática tratou de forma inovadora velhos problemas metafísicos de ordem platônica, sendo precursora de uma nova forma de pensamento, na qual o sentido não pode ser buscado nem na realidade nem na consciência, mas sim construído a partir da linguagem. 
Assim, a "coisa observada", na terminologia palomariana, em razão dessa ruptura, quando se trata do corpo, passa a ser vista não mais como algo eminentemente biológico, característica da lógica tradicional, mas como uma construção sociocultural e linguística, produto e efeito de relações de poder, sendo denominada por Michel Foucault como "realidade biopolítica" (1992, p. 77), produtora de múltiplos e complexos sentidos. Essas novas narrativas que não têm respostas prontas começam a aparecer também nas narrativas jurídicas e literárias, podendo ser percebidas nas formas inovadoras com que muitos escritores constroem seus enredos e personagens, sendo Palomar um entre tantos exemplos.

Nesse contexto, as respostas, a verdade, deixam de ser conteudísticas para assumirem uma "idealização necessária". Nas palavras de Streck: "É uma verdade argumentativa, atingida por consenso. Não há fundamentação válida de qualquer enunciado que não seja pela via argumentativa” (2006, p. 31). Essa via argumentativa passa pela linguagem, mas não no sentido estrito de comunicação. Para Stein, a filosofia fala de linguagem no sentido de que não se trata a linguagem como as ciências, apenas dentro do mundo, como fazem o jurista e o literato. Não trata das linguagens dentro do mundo, mas fala da linguagem enquanto ela é o mundo sobre o qual se fala. Então, é o tratamento filosófico da linguagem que está em questão quando se fala das questões da hermenêutica, ou da hermenêutica filosófica. Tratase de falar do mundo e de se dar conta de que não se pode falar do mundo a não ser falando da linguagem (1996, p. 14). Conforme assevera o citado autor,

A interpretação é hermenêutica, é compreensão, portanto, o fato de nós não termos simplesmente o acesso aos objetos via significado, mas via significado num mundo histórico determinado, numa cultura determinada, faz com que a estrutura lógica nunca dê conta inteira do conhecimento. [...] Isso significa que o nosso acesso aos objetos é sempre um acesso indireto, [...] quer dizer que conhecemos algo como algo. Podemos imaginar um logos que se bifurca: o logos da compreensão da linguagem, que comunica (logos apofântico, que se manifesta na linguagem) e o logos no qual se dá o sentido que sustenta a linguagem (logos hermenêutico, aquele que se dá no compreender) (Stein, 1996, p. 27).

Por isso, Stein afirma que

A hermenêutica filosófica se coloca onde não temos nem o empírico como fundamento nem aquilo que é afirmado 
dentro de um contexto rígido, determinado, nem aquilo que pode ser estabelecido tendo por base o fundamento último, mas aquilo que se dá na fluidez da própria história, da própria cultura. Sabemos que sempre algo escapa na medida em que só se pode fundamentar algo que se chama boa circularidade. Somos incapazes de, no universo hermenêutico, expor todos os pressupostos ou, de certo modo, chegar ao elemento último, não ultrapassável. O universo hermenêutico é exatamente esse universo flutuante (1996, p. 45-46).

Nessa esteira, Streck alerta para o fato de que:

Não interpretamos para compreender, mas, sim, compreendemos para interpretar, deixando claro que a hermenêutica ultrapassa a metafísica, a partir da ideia de que a dualidade de explicar e compreender será sempre precedida por uma compreensão que se dá como condição de possibilidade (Streck, 2006, p. 22).

Consoante Streck, é necessário compreender a grande revolução representada pela viragem linguística, a partir da qual é possível superar os dualismos metafísicos que dominam o imaginário dos juristas, dado que

A verdade real, porque inalcançável, é insustentável filosoficamente, a verdade é uma verdade hermenêutica, que não advém nem do conhecimento das essências e nem de uma mente privilegiada de um sujeito cognoscente. Com a viragem linguística ocorrida na filosofia em nosso século, é preciso ter claro que do processo interpretativo não decorre a descoberta do verdadeiro/correto/unívoco sentido do texto, mas, sim, a produção de um sentido originado de um processo de compreensão, onde o sujeito, a partir de uma situação hermenêutica, faz uma fusão de horizontes a partir de sua historicidade. Não há interpretação sem relação social. Isso porque as palavras da lei não são unívocas mas plurívocas, razão pela qual elabora uma crítica à hermenêutica jurídica tradicional, através dos aportes aproximativos da semiótica (teoria geral da significação) e da hermenêutica filosófica, em que o horizonte de sentido é dado pela compreensão (Heidegger) e ser que pode ser compreendido é linguagem (Gadamer), onde a linguagem não é simplesmente objeto, e sim, horizonte aberto e estruturado e onde a interpretação faz surgir o sentido. [...] A linguagem é analisada não num sistema fechado de referências, mas sim no plano da historicidade, aproximada à práxis humana, como existência e faticidade, em que o texto é ligado a uma existência concreta, a uma carga pré-ontológica que na existência já vem antecipada (1999, p. 79-80).

Nessa tangente, é necessário, também, registrar a constatação de Streck de que:

[...] na sustentação desse imaginário jurídico prevalecente, encontra-se disseminado ainda o 
paradigma epistemológico da filosofia da consciência calcada na lógica do sujeito cognoscente, onde as formas de vida e relacionamentos são reificadas e funcionalizadas, ficando tudo comprimido nas relações sujeito-objeto (Habermas) - carente e/ou refratária à viragem linguística de cunho pragmatista-ontológico ocorrida contemporaneamente, onde a relação ou relações passam a ser sujeito-sujeito. Ou seja, no interior do sentido comum teórico dos juristas, consciente ou inconscientemente, o horizonte a partir de onde se pode e deve pensar a linguagem ainda é o do sujeito isolado (ou da consciência do indivíduo) - que tem diante de si o mundo dos objetos e dos outros sujeitos -, característica principal e ponto de referência de toda a filosofia da subjetividade (1999, p. 92).

Seguindo esse raciocínio, Streck cita Heidegger, para quem 'a linguagem é a casa do ser', Gadamer, para quem 'ser que pode ser compreendido é linguagem', ao afirmar que os contributos da hermenêutica filosófica trazem nova perspectiva para a hermenêutica jurídica, assumindo fundamental importância as obras de Heidegger e de Gadamer. Heidegger, desenvolvendo a hermenêutica no nível ontológico, trabalha com a ideia de que o horizonte de sentido é dado pela compreensão; já Gadamer, ao dizer que ser que pode ser compreendido é linguagem, retoma a ideia de Heidegger da linguagem como casa do ser, ou seja, a linguagem não é simplesmente objeto, e, sim, horizonte aberto e estruturado.

É necessário que se retire proveito dessa viragem linguístico-filosófica e desse giro ontológico propiciado pela hermenêutica, que é justamente a ruptura com as concepções metafísico-objetificantes através da mediação da linguagem: o fato de nós não termos simplesmente o acesso aos objetos via significado, mas via significado num mundo determinado, numa cultura determinada, faz com que a estrutura lógica nunca dê conta inteira do conhecimento, de que não podemos dar conta pela análise lógica de todo o processo de conhecimento. Desse modo, fazer hermenêutica jurídica é realizar um processo de compreensão do Direito. Fazer hermenêutica é desconfiar do mundo e de suas certezas, é olhar o Direito de soslaio. Com a compreensão hermenêutica do Direito recupera-se o sentido-possível-de-um-mundodeterminando-texto e não a re-construção do texto advindo de um significante-primordial-fundante. Talvez por acreditar em sentidos a priori ou em verdades apofânticas, é que os aplicadores do Direito, inseridos na já delineada crise de paradigma, consigam (re)produzir decisões sem se darem conta das repercussões sociais e da própria função social dele - jurista - e do (des)cumprimento do texto constitucional (1999, p. 108). 
Também nesse rumo, recentemente, Ost referiu a importância da compreensão dessa ruptura de modelos graças à compreensão de que somos seres de linguagem:

\begin{abstract}
A partir do momento em que somos seres de linguagem, exprimindo-nos através de palavras e de textos, penso que é o conjunto das ciências humanas e sociais, e não somente das ciências jurídicas, que pertence à arte de compreender. O paradigma hermenêutico caracteriza-os, polarizado pela questão, infinitamente relançado, do sentido, antes que o paradigma analítico, infelizmente dominante hoje, que crê poder raciocinar em termos de verdade não contestada e de encerramento lógico (2017, p. 267).
\end{abstract}

É nesse norte que segue Palomar, trilhando caminhos conhecidos e desconhecidos, o racional e o sensível unindo-se na complexa tarefa de relacionar os objetos de suas observações com o mundo, ou entre ele e os objetos, ou entre ele e o mundo. Mesmo sem certezas, continua sua busca, consciente de que "[...] o importante não é tanto dizer a coisa certa, quanto dizê-la partindo de premissas e implicando consequências que deem à coisa dita seu máximo valor" (Calvino, 1994, p. 94).

No entanto, Palomar duvida de suas próprias conclusões e ilações, pois, embora tente construir um modelo ideal por meio do qual pudesse extrair conclusões precisas de suas observações, depara-se com a impossibilidade da total compreensão do mundo:

Houve na vida do senhor Palomar uma época em que sua regra era esta: primeiro, construir um modelo na mente, o mais perfeito, lógico, geométrico possível; segundo, verificar se tal modelo se adapta aos casos práticos observáveis na experiência; terceiro, proceder às correções necessárias para que modelo e realidade coincidam. Esse procedimento parecia a Palomar o único capaz de lhe permitir enfrentar os mais emaranhados problemas humanos. [...] O modelo é por definição aquele em que não há nada a modificar, aquele que funciona com perfeição; ao passo que a realidade, vemos bem que ela não funciona e que se esfrangalha por todos os lados; portanto, resta apenas obrigá-la a adquirir a forma do modelo, por bem ou por mal (Calvino, 1994, p. 97-98).

Então, após diversas tentativas e muitas vezes relutando, Palomar passou a aceitar a ideia de que a realidade somente pode ser compreendida por vários modelos, e não apenas por um, justamente porque os ângulos são diversos, assim como diversos são os que olham, de tal modo que tais 
modelos precisam estar em permanente estado de construção/reconstrução, adaptáveis às realidades e complexidades que os cercam:

A regra do senhor Palomar foi aos poucos se
modificando: agora já desejava uma grande variedade de
modelos, se possível transformáveis uns nos outros
segundo um procedimento combinatório, para encontrar
aquele que se adaptasse melhor a uma realidade que por
sua vez fosse feita de tantas realidades distintas, no
tempo e no espaço. [...] Só lhe falta expor esses belos
pensamentos de forma sistemática, mas um escrúpulo o
retém: e se daí decorresse um modelo? Assim prefere
manter suas convicções em estado fluido, verificá-las caso
a caso e fazer delas a regra implícita do próprio
comportamento cotidiano, no fazer ou no não-fazer, no
escolher ou no excluir, no falar ou no calar-se (Calvino,
1994, p. 99-10o).

Assim, evidencia-se a atividade do olhar, por meio do qual tornaramse possíveis suas observações, de modo que Palomar “[...] ensaia várias formas/modos de olhar/ler, experimenta vários ângulos, mas esse olhar não é um reflexo do universo, pois a visão é refratada, o mundo é um simulacro nessa atividade crítica-reflexiva" (Hellmann, 2010, p. 54).

Segundo o olhar palomariano, talvez fosse necessário usar diferentes métodos, aproximar-se da realidade por diferentes caminhos, olhar para ela desde diferentes pontos de vista, porque a realidade é, de fato, inatingível por uma só via; mas nem por isso Palomar deixa de querer compreendê-la, propondo-se a lançar novos e desordenados olhares em suas observações:

Cada processo de desagregação da ordem do mundo é irreversível, mas os efeitos são escondidos e retardados pelas miríades de grandes números que contêm possibilidades praticamente ilimitadas de novas simetrias, combinações, acoplamentos (Calvino, 1994, p. 92).

A solução parece encontrar-se na escolha de um ponto de vista: é a partir de determinada perspectiva que se pode construir o relato; é a partir de um ponto de vista previamente estabelecido que é possível aproximar-se da realidade:

[...] a coisas que deve observar são apenas algumas e não todas, e é à procura dessas que deve andar; para tanto precisa enfrentar a cada instante problemas de escolhas, exclusões, hierarquias de preferências; logo, se dá conta de que está arruinando tudo como acontece toda vez que mete no meio seu próprio eu e todos os problemas que tem com o próprio eu (Calvino, 1994, p. 101-102). 
Palomar lembra que é difícil a escolha e que uma vez realizada, tornase necessário aceitar que se trata apenas de uma perspectiva; uma perspectiva que poderá dar conta da realidade de uma maneira melhor ou pior do que outras perspectivas, mas que nunca dará conta do total da realidade, por numerosas que sejam suas tentativas, por maiores que sejam seus esforços.

Tanto é assim que, na viagem a um dos monumentos mais importantes da civilização japonesa, o jardim de pedras e areia do Templo Ryoanji de Quioto, Palomar começa a observar um pequeno pátio recoberto de areia branca de grãos grossos, as rochas, as árvores, enfim, tudo aquilo que o compunha, mas estava espremido no meio de muita gente. No relato, o narrador refere que:

Podemos ver o jardim de areia como um arquipélago de ilhas rochosas na imensidade do oceano, ou antes como o cimo de altas montanhas que emergem de um mar de nuvens. Podemos vê-lo como um quadro emoldurado pelos muros do templo, ou esquecer-nos das molduras e convencer-nos de que o mar de areia pode se expandir sem limites e cobrir todo o mundo. [...] Mas esta conclusão que conduz à habitual nostalgia de um paraíso perdido pela invasão de uma civilização de massa soa demasiado fácil ao senhor Palomar. Ele prefere meter-se por um caminho mais difícil, procurar compreender aquilo que o jardim zen lhe pode oferecer à vista na situação específica em que pode ser observado hoje, esticando o próprio pescoço em meio a outros pescoços (Calvino, 1994, p. 86-87).

No trecho da obra que aqui se analisa, é interessante observar que as viagens são utilizadas como pano de fundo, o que se verifica na medida em que os eventos situam-se no México e no Japão, não sendo sem razão o uso de tal estratégia. Ao fazê-lo, o narrador acompanha Palomar e assume o estatuto do narrador viajante benjaminiano, cuja relação se explica na sequência.

Profundo conhecedor das várias linguagens artísticas, Walter Benjamin (1999) elenca as figuras do camponês sedentário e do marinheiro comerciante em seu conhecido ensaio "O narrador". O filósofo, historiador e crítico literário responsabiliza o viajante por uma das formas básicas de narrar. Embora associe a narrativa à tradição oral e o romance à escrita, Benjamin eleva a viagem à condição de motivo primordial da Literatura, como bem exemplifica Palomar. Assim, é possível afirmar que os dois 
grupos benjaminianos - o camponês sedentário e o marinheiro comerciante - são metáforas que representam um espaço mais limitado, no primeiro caso, e uma ampliação do espaço, vinculada ao deslocamento propiciado pela viagem, no segundo caso.

O conhecimento do narrador-viajante imbrica-se a uma reflexividade através da escrita, quando a viagem se torna um operador da cognição. $\mathrm{O}$ narrador encontra-se numa posição exotópica, a qual, sendo o locus do olhar sobre a alteridade, permite conhecer o outro por meio de variantes como costumes, religião, língua, povo, Estado etc. Tais elementos relativizam o familiar, o cotidiano, ao mesmo tempo em que interrogam o estranho (Remédios, 2004, p. 287), propiciando situações de reflexão a desvelar novas possibilidades de compreensão do mundo, como acontece em Palomar, a exemplo do trecho a seguir transcrito:

Que vê? Vê a espécie humana na era dos grandes números estendendo-se numa multidão nivelada mas feita de individualidades distintas como esse mar e grãozinhos de areia que submerge a superfície do mundo... Vê o mundo nada obstante continuar a mostrar os dorsos de granito de sua natureza indiferente ao destino da humanidade, sua dura substância irredutível à assimilação humana... [...] E entre humanidade-areia e mundo-escolho intui-se uma harmonia possível como entre duas harmonias não homogêneas: a do nãohumano num equilíbrio de forças que parece não corresponder a nenhum desenho; a das estruturas humanas que aspira a uma racionalidade de composição geométrica ou musical, jamais definitiva... (Calvino, 1994, p. 87).

Em seus deslocamentos, o narrador tece observações graças ao olhar de Palomar, mais atento do que o convencional de uma situação cotidiana de não viagem, um olhar que não percebe as coisas de forma atemporalizada, mas presentes, de forma única, com luzes e cores exatas apenas naquele instante preciso sobre o qual recai sua observação. Muitas vezes, trata-se de algo aparentemente corriqueiro, sem nada de especial a destacar, mas que, sob determinada luminosidade oferecida pelo olhar de Palomar, adquire significado especial no relato do narrador, a exemplo dos diferentes pontos de vista apontados por Galeano em sua obra "De pernas para o ar: a escola do mundo ao avesso" (2015).

Assim, o narrador viajante acompanha o inseparável espírito investigativo de Palomar e sua tendência ao olhar admirativo, 
contemplador, incorporador do outro e de seus sinais históricos, naturais, paisagísticos, culturais, entre outros. Ao encarar o objeto observado dessa maneira, Palomar nele detém seu olhar, o qual se processa em conformidade com a informação e a sensibilidade de cada objeto, de cada momento, de cada contexto:

\begin{abstract}
Não basta que Palomar observe as coisas por fora e não por dentro: daqui por diante irá observá-las com um olhar que vem do exterior, não de dentro de si mesmo. Procura logo fazer a experiência: agora não é ele que está olhando, mas é o mundo exterior que olha para fora. Isto estabelecido, gira o olhar em torno à espera de uma transfiguração geral. Mas qual! É a costumeira mesmice cotidiana que o circunda. Precisa reestudar tudo desde o princípio. Não basta que seja o exterior que esteja observando o exterior: é da coisa observada que deve partir a trajetória que a associa à coisa que observa (Calvino, 1994, p. 102).
\end{abstract}

Dessa maneira, o olhar de Palomar leva-o a experiências singulares, as quais se revelam no aflorar de suas impressões, quando o impacto diante do desconhecido induz a um desejo de abarcá-lo; daí as várias metáforas e analogias empregadas pelo narrador para relatar as experiências de Palomar, marcadas pelo encontro com o novo num permanente esquema de semelhanças e diferenças que enriquecem os ângulos de visão do olhar palomariano, pautado pela convicção de Calvino quanto à importância do papel da Literatura para atingir tais objetivos.

Ítalo Calvino, em 1985, portanto, há mais de trinta anos, quando escreveu cinco conferências para a Universidade de Harvard e que, devido a sua morte, nunca foram proferidas, realizou uma profunda reflexão sobre cinco das qualidades da escritura (a sexta seria tema da última conferência, jamais escrita), daí o título de "Seis propostas para o novo milênio". Por meio delas, Calvino busca uma concepção de Literatura como transparência e lucidez, com instrumentos e objetos próprios, num verdadeiro projeto de resistência ao empobrecimento da língua, que ele constata e critica:

Às vezes me parece que uma epidemia pestilenta tenha atingido a humanidade inteira em sua faculdade mais característica, ou seja, no uso da palavra, consistindo essa peste da linguagem numa perda de força cognoscitiva e de imediaticidade, como um automatismo que tendesse a nivelar a expressão em fórmulas mais genéricas, anônimas, abstratas, a diluir os significados, a embotar os pontos expressivos, a extinguir toda centelha que crepite no encontro das palavras com novas circunstâncias. Não me interessa aqui indagar se as origens dessa epidemia 
devam ser pesquisadas na política, na ideologia, na uniformidade burocrática, na homogeneização dos massmedia ou na difusão acadêmica de uma cultura média. $\mathrm{O}$ que me interessa são as possibilidades de salvação. A literatura (e talvez somente a literatura) pode criar os anticorpos que coíbam a expansão desse flagelo linguístico (1990, p. 74).

Portanto, como as viagens de Palomar, enquanto temáticas literárias, envolvem sempre deslocamento e contato com o outro, seus relatos inevitavelmente registram a paisagem natural e humana, a partir da qual surgem reflexões diversas e inesperadas que o desconcerta em suas aparentes certezas, razão pela qual é possível afirmar que os relatos das viagens palomarianas são, por excelência, o espaço da criação do outro, mas também de um eu palomariano que, na viagem, constrói a imagem do outro e de si mesmo. É esse olhar multicultural que leva Palomar à experiência do estranhamento, proporcionado pelo novo, um novo que somente o é porque o olhar assim determina.

Isso gera sentimentos, emoções e, em especial, inquietações que podem ser também sentidas em diferentes áreas do conhecimento, a exemplo do Direito, na medida em que as chamadas Ciências Jurídicas e Sociais sofrem a influência de uma teoria imaginária. Para melhor compreender tal confluência, a Teoria poética do direito pode ser empregada e, para tanto, utilizam-se, neste estudo, os ensinamentos de Willis Santiago Guerra Filho.

\section{TEORIA POÉTICA DO DIREITO}

Nesse itinerário, depois das viagens de Palomar, a excursão rumo ao objetivo proposto neste texto continua na obra de Willis Santiago Guerra Filho, visitando suas diferentes impressões e interpretações que levam à Teoria poética do direito. A imaginação literária não pode estar alheia ao Direito, e este não pode estar alheio àquela, porque o Direito também é linguagem. Isso já se pode perceber nas inquietações palomarianas antes relatadas e segue cunhado por Guerra Filho, que se utilizou da expressão "Teoria imaginária do direito" para melhor definir essa inter-retro-relação. De acordo com o referido autor, tal teoria apresenta uma postulação epistemológica e outra ontológica. A primeira, referente à natureza da Teoria do Direito, aponta para o seu caráter imaginário, enquanto que a 
segunda, "referente à natureza do próprio Direito, objeto de uma tal teoria, também aponta para o seu caráter imaginário enquanto fome de saber (Guerra Filho; Cantarini, 2014, p. 23).

A postulação epistemológica referida confronta-se com a tradição racionalista, cartesiana, a qual reverbera, na concepção sartreana sobre o imaginário, "a imagem, como um símbolo deficiente, ontologicamente esvaziado, a ser superado pelo conceito, correlato da atividade racional" (Guerra Filho; Cantarini, 2014, p. 23).

No que tange à postulação ontológica, ou seja, no caráter imaginário do próprio Direito enquanto objeto de estudos teóricos, é necessário ter em conta que o Direito é também uma forma de conhecimento, um modo como a sociedade dá a conhecer aos seus membros o comportamento que é esperado de cada um deles pelos demais. Essas duas postulações, a epistemológica e a ontológica, convergem, mostram-se como "os dois lados de uma mesma moeda”, que destacam o caráter fundamentalmente "po(i)ético", criativo, imaginativo de toda obra humana, aí incluídos tanto o Direito como o conhecimento que se produz, a seu respeito, e também em geral, a totalidade do que se conhece, enquanto dependente de alguma forma de decodificação" (Guerra Filho; Cantarini, 2014, p. 25).

No intuito de melhor explicar a utilização de uma teoria imaginária ou poética no Direito, a sua interface com a Literatura, Nussbaum refere que, exemplificativamente, certas situações podem despertar no leitor emoções que o levem a descobrir que muitas vezes a atitude de um personagem é motivação para que também ele aja daquela maneira. É nesse sentido que Nussbaum denomina esse tipo de imaginação de 'imaginação literária', já que ela vai sendo formada a partir da Literatura (1997).

No entanto, não se pode deixar de observar que os juízos no universo ficcional diferem daqueles da realidade propriamente dita; afinal, a "realidade" da ficção é uma simulação. O mesmo, entretanto, não se pode dizer dos juízos realizados no Direito, que se referem a um possível "estado de coisas", a uma realidade no âmbito do dever ser, "dotada de um caráter vinculante, que a impõe como se realidade fosse, na qual se deve acreditar, e isso para evitar que, em razão do descrédito, venha-se a sofrer consequências bem reais, como são as sanções jurídicas" (Guerra Filho; Cantarini, 2014, p. 33-34). 
O Direito disponibiliza aos sujeitos meios de produzir uma história, vinculante para os que dela fizerem parte, no sentido de aquisição de direitos e deveres e de obediência ao previamente estabelecido, codificado, como o enredo (Guerra Filho; Cantarini, 2014, p. 34), revelando-se, assim, a importância do sentimento e das emoções para os aplicadores e estudiosos do Direito, além da faculdade da imaginação: o Direito é visto como mero instrumento técnico, de controle do comportamento, da conduta humana, sem percebê-lo também como tendo o ônus de se justificar, de fundamentar o que apresenta como válido, para além da simples referência a normas postas, porque é uma visão tecnicista a que predomina. É preciso, então, implicar mais o sujeito encarregado da interpretação e aplicação das normas nesse processo, com sua vivência do drama que tem diante de si. De acordo com os autores,

[...] se precisa prestar mais atenção atualmente, que é o próprio sentimento ou a sensibilidade dos que estarão sujeitos a estas ordenações, para que estas ordenações não sejam percebidas e, de fato, implementadas de uma maneira que desconsidera a dignidade própria destes sujeitos. E é aí que entendo tenhamos que desenvolver uma abordagem poética do direito. A Poética é uma disciplina filosófica que remonta a Aristóteles, em seu tratado da Poética, portanto, deste que é um dos autores do cânone filosófico padrão do pensamento ocidental, sendo que desta obra o que restou foi, sobretudo, a teorização sobre a tragédia. Penso que aí nós temos realmente uma chave para ser utilizada também para reavaliar o pensamento teórico, como um todo e, claro, igualmente do campo do direito, considerando aquela faculdade um tanto quanto desprezada tradicionalmente, que é a faculdade da imaginação (Guerra Filho; Cantarini, 2014, p. 151).

Nesse sentido, os autores citados, a exemplo do que já fazia Dworkin na obra Uma questão de princípio, mais especificamente no capítulo "De que maneira o Direito se assemelha à literatura" (2000, p. 217-254), quando sustenta a tese de que a prática jurídica é "um exercício de interpretação, não apenas quando juristas interpretam documentos ou leis específicas, mas de modo geral" e de que "poderemos melhorar nossa compreensão do Direito comparando a interpretação jurídica com a interpretação em outros campos do conhecimento, especialmente a literatura" (2000, p. 217), e Martha Nussbaum, que afirma a necessidade de uma interpretação jurídica em uma interface com a Literatura, defendem 
que o Direito deve ser reconhecido como imaginário, no sentido de ficcional, um produto do desejo:

[..] é o direito visto, percebido e concebido sempre in fieri, nunca pronto e acabado, donde o caráter autopoiético do direito e a necessária e indissolúvel vinculação dele com a filosofia e com o teatro, sobretudo aquele que surge com ela, na Grécia antiga. Eis o que se pode considerar uma síntese da Teoria Poética do Direito. É este um caminho para o reconhecimento da alteridade como fundamento dos direitos humanos, do qual se destacam o direito ao amor, o direito a não ficar submisso, o direito de ser diferente, original e criativo e o direito a transitar à margem dos lugares comuns (2014, p. 139-140).

O Direito faz parte desse universo lúdico, criação do desejo humano, um modo de imaginar o real em descrições que façam sentido, como diria o antropólogo Cliford Geertz (Guerra Filho; Cantarini, 2014, p. 36-37). Dworkin entende que o ponto que aproxima a seara jurídica da literatura, do ficcional, do imaginário, é justamente a interpretação. Ao retratar um esforço de imaginação literária, ele refere que:

Decidir casos controversos no Direito é mais ou menos
como esse estranho exercício literário. A similaridade é
mais evidente quando os juízes examinam e decidem
casos do Common Law, isto é, quando nenhuma lei
ocupa posição central na questão jurídica e o argumento
gira em torno de quais regras ou princípios de Direito
'subjazem' as decisões de outros juízes, no passado, sobre
matéria semelhante. Cada juiz, então, é como um
romancista na corrente. Ele deve ler tudo o que os outros
juízes escreveram no passado, não apenas para descobrir
o que disseram, ou seu estado de espírito quando o
disseram, mas para chegar a uma opinião sobre o que
esses juízes fizeram coletivamente, da maneira como cada
um de nossos romancistas formou uma opinião [...]
(200o, p. 236).

A interpretação deve ser realizada de modo a pensar corretamente o direito para aplicá-lo às questões mais simples ou mais complexas que permeiam o mundo complexo. Nesse sentido, Streck questiona o "senso comum dos juristas”, já trabalhado por Luis Alberto Warat (1979), fazendo um apelo à literatura e ao uso das narrativas, porque a arte literária humaniza o Direito (2006).

O Direito, então, ao invés de meramente positivo, haverá de "ser concebido antes como possível, imaginário, pois a ficção é a verdade do Direito, e o Direito é a camuflagem do poder apropriado e exercido pelos 
“autores-intérpretes" desta grande montagem, que é a sociedade" (Guerra Filho; Cantarini, 2014, p. 41). Daí que o tipo de discurso a ser desenvolvido no âmbito da teoria jurídica deveria ser "um discurso ficcional, poético, ou melhor, "poiético" (do grego poiésis, "fazer”, "produzir", “criar”)", para melhor "poder imaginar várias versões para a história da origem do humano, permanecendo sempre o mesmo desfecho, a saber, o de sermos um ser produzido pelas proibições que se nos impõem e, logo, também, impomo-nos" (Guerra Filho; Cantarini, 2014, p. 42).

Trata-se, então, de realizar um trabalho imaginativo, conscientemente ficcional, que se avalia - e avaliza - por seus efeitos, e, nessa perspectiva, a Mitologia, a Filosofia, o Direito ou a religião e mesmo as demais ciências são literatura, ficções; “o que se pretende fazer é contar uma história o melhor possível, para torná-la verossímil”, dando sentido às suas vidas (Guerra Filho; Cantarini, 2014, p. 36-37).

É preciso que, na seara jurídica, defenda-se a racionalidade

[...] contemplando o solo mesmo de onde ela brota, o húmus da cultura donde emerge o humano: a capacidade simbolizadora presente na linguagem, em suas mais diversas formas (sendo o direito uma delas), enquanto produtora (e produto) do esforço de produção de um sentido para a existência desse ser em aberto, livre, que somos. Do que faz falta, então, é de promover uma (re)aproximação da teoria a um modo antes poético, do que científico e mesmo filosófico (ou religioso), de desenvolver a reflexão e sua exposição (Guerra Filho; Cantarini, 2014, p. 49-50).

Há, então, necessidade de que se pratique uma perspectiva não reducionista e não simplificadora, mas capaz de articular explicações de natureza sociológica, econômica, jurídica, biológica, filosófica e, até, teológica (Guerra Filho; Cantarini, 2014, p. 69).

Se o ser humano não pode ser conhecido somente por partes, mas deve ser compreendido a partir de um jogo complexo, num movimento circular ininterrupto, como já dizia Edgar Morin, que leva em consideração as paixões, as emoções, as dores e as alegrias que são inerentes à condição humana, é justamente porque uma Teoria poética do direito faz-se necessária para que o Direito possa realmente criar condições para o desenvolvimento da capacidade crítica.

O próprio Palomar faz uma pertinente crítica ao recorte das disciplinas, das ciências, as quais impossibilitam aprender e compreender o 
que foi tecido junto, em seu sentido original, que é sempre mais complexo do que quer fazer crer a tese do reducionismo3, que restringe o complexo ao simples. O princípio da redução não pode ser aplicado para se conhecer, estudar uma ciência como a jurídica, já que essa trabalha com os problemas dos seres humanos, que, por sua natureza, são seres complexos.

Isso tudo deve ser desdobrado em um espaço de busca estética, de provocação, de reflexão, de interrogação, de compartilhar experiências, numa verdade que representa uma verdadeira postura emancipatória frente à vida:

\begin{abstract}
A humanidade, em grande parte, vive o superficial. São milhões que nascem, crescem... será que morrem? Talvez nem tenham chegado realmente a sentirem-se vivos. E nós, em que dimensão da realidade queremos viver e construir para aqueles que nos sucederão? Queremos olhar o mundo com os olhos da vida, no seu processo inaudito, ou deixar que o mundo limite a visão do sentido de existir com olhos mecânicos da técnica? (Silva; Maragon; Rosa, 2009, p. 37).
\end{abstract}

Assim como as pessoas, o Direito também está e deve estar em constante construção, porque depende da subjetividade dos seus destinatários, intérpretes e aplicadores, daí a opção por conceituá-lo como sinônimo de sonho, "com o mesmo caráter deste, enquanto fruto do desejo humano, e não apenas da vontade objetiva ou de necessidades, primárias ou secundárias, noções falseadoras em que se baseia o utilitarismo tecnicista hoje existente" (Guerra Filho; Cantarini, 2014, p. 147).

O teatro, a filosofia e o Direito configuram instrumentos imprescindíveis no que diz respeito à identificação dos interesses, desejos e sentimentos "do outro", ampliando o olhar para este outro. Por isso, relacionar teatro, literatura, filosofia e Direito, para assim favorecer o questionamento da origem produtora das alterações trazidas ao mundo por

3 O reducionismo, a partir do método, é a ênfase na abordagem de elementos isolados, fragmentados, analíticos, compartimentados. É a fragmentação do saber e das disciplinas. Tal fragmentação e o papel diretivo do método geram a perda da dimensão da complexidade e da interdependência de fatores, ou seja, a visão sistêmica e sintética, já que a visão imperante é analítica. A complexidade exigiria cuidados procedimentais redobrados e um princípio de precaução que "atrasariam” o chamado progresso. Abre-se caminho para um materialismo científico, na consideração de elementos de ordem físicoquímica, para o predomínio absolutista das ciências naturais e seu estatuto epistemológico-metodológico sobre todo o saber. Conduz ao determinismo científico, a uma abordagem mecanicista que retira a ambiguidade, o mistério e a complexidade das realidades ou dos seres vivos. O que significa também dizer da perda da visão holística do todo, da unidade e da participação da consciência no mundo (Pelizzoli, 2007). 
esse modo humano de ser, permite atingir uma melhor compreensão do homem e do Direito, que tanto é produzido por ele como o produz, compreendendo melhor o outro (Guerra Filho; Cantarini, 2014, p. 139 e 148). Tal subjetividade está relacionada à emoção, seja qual for a temática de que se esteja tratando, visto que

Uma argumentação sobre o respeito, a ética, os direitos humanos não convence a ninguém que já não esteja convencido. Porque não é a razão que justifica a preocupação pelo outro, mas é a emoção. Fazemos todo um discurso maravilhoso e impecável, mas que não serve para nada, não porque não esteja impecável, mas porque não faz referência ao espaço de aceitação mútua no qual a preocupação ética tem sentido (Maturana, 2001, p. 61).

Isso implica que também as emoções, a subjetividade, devem fazer parte do interpretar, do compreender. Elas (as emoções) não são inimigas da razão, porque, se o fossem, estar-se-ia negando sua condição no ser humano. Por isso,

O importante, para não incorrer em equívocos, seria escolher as emoções que partem da racionalidade e potencializá-las, pois não se poderia, em nome da neutralidade, apagar a emoção, sob pena de as decisões se tornarem extremamente abstratas e calculadas distantemente da realidade daqueles a quem se destinam. No que se refere às decisões judiciais, então, não se poderia esquecer que elas são proferidas para alguém e não apenas para algo (Duarte; Maders, 2016, p. 166).

As narrativas literárias, a ficção, a arte, em si, reproduzem experiências reais de forma estilizada, dramatizada, as quais são capazes de construir um imaginário comum, não meramente individual, mas coletivo, e, ao serem publicadas, passam a ter uma dimensão de recuso coletivo. Então, de acordo com Nussbaum, ao contrário do modelo vigente de justiça, não deve haver o afastamento das emoções para que haja maior imparcialidade e neutralidade nos julgamentos, na medida em que elas auxiliam a ver o todo de um modo mais autêntico.

Martha Nussbaum reconhece que falta um ingrediente essencial de humanidade na lógica racionalista dominante que podia ser denominado de visão poética do mundo. Se entendermos como Heidegger que a intuição poética de artistas e escritores é a que melhor capta a essência das coisas, podemos ver nas obras de arte e na literatura um contributo valioso para nos ensinar a olhar o mundo de modo mais verdadeiro (Silva, 2006, p. 158). 
Compreender não se resume a subsumir fatos a textos, ou vice-versa, ou recuperar uma suposta intenção do autor. Compreender pressupõe diversos encontros e significa

[...] dar-se conta que a construção de sentidos está relacionada com a obra aberta por determinadas condições de possibilidade, pois compreender é uma manifestação ôntica do existente. De outra banda, tal dimensão criativa do ato de aplicar textos jurídicos não importa defender a existência de uma absoluta liberdade de dizer o sentido jurídico. Nesse aspecto, as narratividades produzidas são elementos fundamentais para focar o diálogo, possibilitando o surgimento do roteiro da obra, das perguntas colocadas pela historicidade da compreensão (Ohlweiler, 2008, p. 195-196).

Esse modelo de compreensão representa o poder revolucionário da Literatura, como afirma Nussbaum (1997), porquanto a Literatura e a imaginação poética são subversivas, criam critérios de empatia e reconhecimento das diferenças, razão pela qual a autora afirma que sem a Literatura, os juízes não podem ser bons juízes, os legisladores bons legisladores, os economistas bons economistas (apud Duarte; Maders, 2016, p. 168).

Nesse norte, retornando a Calvino, que serviu de base para a parte inicial deste texto com as viagens de Palomar, cabe destacar que ele já referia que a literatura é a Terra Prometida em que a linguagem torna-se aquilo que na verdade deveria ser (1990, p. 74), o toque de Midas para a ciência jurídica. Assim, para que o manancial de possibilidades propiciadas pela linguagem seja melhor explorado, o jurista deve assumir uma postura crítico-sensível, afastando-se do perfil tradicional, que "considera o Direito como um sistema de normas onde domina por excelência a palavra, a manifestação do dito, do escrito, do conhecimento e pensamento simbólico" (Sbizera, 2015, p. 135). Isso porque o modelo tradicional

[...] forma juristas sem sensibilidade, corpos sem capacidade de se relacionar sensivelmente com os outros e com o mundo, incapazes de perceber e literalmente escutar os sentimentos das pessoas. Em um tempo onde todo modo de comunicação que quer ser eficaz deve passar também pelo tato, pelo som e pela imagem, o Direito permaneceu no estágio do discurso e, primordialmente, do discurso escrito, redigido. Sua razão de ser consiste na existência de normas pelo menos incitativas ou persuasivas, mas muito mais prescritivas, imperativas ou proibitivas, no que concerne aos comportamentos individuais e sociais eventuais. Se estes comportamentos estão submergidos na realidade, o 
Direito parece os levar em consideração somente quando substitui o real pelos signos. A partir daí nasce uma atuação do Direito que constitui uma operação de desvio da realidade. $\mathrm{O}$ que era mundo, movediço, múltiplo e contraditório, reduz-se e torna-se palavra na lei e no processo [...] (Sbizera, 2015, p. 135).

O Direito, nessa toada, há de ser reconhecido como imaginário, no sentido de ficcional, um produto do desejo, com o mesmo estatuto dos sonhos, mas um sonho coletivo e semiconsciente; pois

[...] o Direito nada mais é do que a visão local e temporalmente recortada por um humano detentor da capacidade e função de dizer o direito como um acontecimento real. Outro humano, dirá outro direito. Funciona o Direito, então, como um sistema fictício, mas colocado na realidade ao abrigo dos imaginários individuais e coletivos não iniciados e subversivos. Ao cristalizar uma determinada compreensão, não apenas rejeita outras possíveis, senão que também mumifica tudo o que, originalmente, estava vivo (Sbizera, 2015, p. 136).

Portanto, para ser criativo, dinâmico e plural, o Direito precisa da Literatura, na medida em que esta é um lugar privilegiado de formação do jurista crítico-sensível, "um dos lugares mais capazes de tornar apto o aprendizado e o uso de conhecimentos e pensamentos que para muito além das palavras, vai à realidade, ao sensível e ao humano, do humano" (Sbizera, 2015, p. 139). Frente à dinamicidade do Direito, a teoria desenvolvida por Ost (2009) acerca dos três modelos de juízes anteriormente referida e comparada aos personagens da obra de Calvino trabalhada neste artigo é insuficiente, especialmente no caso brasileiro, tanto que criticada, dado que não existe um modelo de juiz ou três, assim como não existe um modelo de Justiça, ainda mais na era da complexidade. Um desses críticos é Lenio Streck em sua obra Verdade e consenso (2006). Além dele, Rafael Tomaz de Oliveira e Alexandre Morais da Rosa (2013) sugerem um novo arquétipo de juiz adequado ao senso comum teórico dos juristas brasileiros, o qual enunciam "complexo MacGyver".

No Direito, é preciso reduzir um fato da vida das pessoas - que talvez tenha perdurado por um longo período de tempo e esteja envolto em uma série de acontecimentos e sentimentos - a poucas páginas de um texto, seja para peticionar, seja para julgar. Por isso, é ilusão acreditar na completude e na unicidade do mundo jurídico, quando, na verdade, o Direito é polifônico, como o é a própria vida; os seres humanos, a palavra e a 
linguagem. Assim, na esteira de Ost (2004) e corroborando que o Direito é, de fato, palomariano, a aproximação entre Direito e Literatura conduz à dupla inversão: a inversão do possível e do real e a inversão do singular e do universal.

A primeira consiste em testemunhar que o próprio real não é outra coisa senão uma modalidade do possível, ou seja, trata-se de enxergar a realidade pelo espelho da ficção. Já a segunda inversão leva o pensamento a conceber o particular como uma entidade que somente existe deixando-se subsumir sob o império do universal, delineando-se, assim, um universo bem ordenado, marcado pela lógica linear e classificações estritamente hierarquizadas que, no ato da inversão pelo imaginário, propõe intrigas singulares que têm por efeito desarranjar e desafiar o universal formal que gostaria de codificar todo o real; trata-se de (des)ocorrer por rupturas (Ost, 2004).

Desse modo, o estudo do Direito pode tornar-se crítico na medida em que se movimenta, alternando a perspectiva do olhar do observador, e faz de si mesmo um objeto a ser estudado a partir de fora, usando uma linguagem extrajurídica, uma metalinguagem, a qual pode ser oriunda das mais diversas áreas do conhecimento humano, a exemplo da Literatura. Assim, quando direcionada pelos juristas ao estudo do Direito em aproximações não redutoras, começa-se então a estudar o Direito criticamente, a partir, necessariamente, da modificação na linguagem proporcionada por um arsenal de categorias e referenciais que o Direito por si só se recusa a utilizar e sequer é capaz de perceber (Sbizera, 2015, p. 125-127).

\section{CONSIDERAÇÕES FINAIS}

Os ângulos palomarianos colocam a questão da relação do sujeito com o outro, entremeada pela linguagem; daí a densidade dos personagens. Expressam essa transição de paradigmas, na qual a linguagem é vista como o elemento estruturador da relação do ser humano com a realidade. Principalmente a partir de Habermas, é relativizada a objetividade da ciência para serem enfatizadas as narrativas, as relações intersubjetivas e culturais, a hermenêutica, a partir de diferentes leituras da realidade proporcionadas por diferentes modelos e pela pluralidade de linguagens. $\mathrm{O}$ "mundo da vida" e o "horizonte de sentido", na esteira de Habermas e 
Gadamer, respectivamente, apenas se tornam possíveis por meio da linguagem, abrindo novos horizontes hermenêuticos.

Tal pensamento é perceptível na obra de Ítalo Calvino, pois os olhares de Palomar revelam que a única verdade que se pode encontrar é a da certeza e a da ambiguidade dos conceitos buscados, bem como que aqueles significados apresentados tanto podem ser verdadeiros quanto podem ser obscurecedores da verdadeira definição, porque podem reduzi-la ou reificála e, por isso, devem ser lidos como respostas temporárias.

Como se pôde perceber, ao aplicarmos a Teoria do direito na leitura de Palomar, evidencia-se que a Literatura funciona como veículo de ideias, enquanto reflexão sobre a realidade social, enquanto expressão do pensamento de um autor. É graças ao efeito literário do estranhamento que o mundo cotidiano transforma-se em algo não familiar: ela tem o condão de trazer uma consciência dramática da linguagem. Por isso, quando a Literatura luta com a linguagem de forma mais trabalhosa, mais autoconsciente que o usual, ela renova o mundo encerrado por essa linguagem (Eagleton, 2006).

As idiossincrasias literárias têm o condão de operar essa mágica: aumentar a capacidade de ver e de sentir. A Literatura satisfaz necessidades básicas do ser humano, enriquecendo a percepção e a visão de mundo. Não é por nada que é possível conhecer o Direito pela arte, reconstruindo imagens sobre o mundo jurídico e aperfeiçoando o repensar sobre sua inserção social, sobre o seu papel e sua imagem sociais. Portanto, os ângulos palomarianos abordados no presente estudo trazem a questão da abordagem do Direito pelo viés da Literatura, de forma a permitir melhor compreensão do Direito por parte de seus profissionais, nos quais provoca angústias e fascínios.

A Literatura, por meio do seu discurso, é em si uma condição de possibilidade de produção de novos discursos, capazes de transformar a realidade. Trata-se de uma das funções da Literatura enquanto arte: a função social, com objetivo social, altruístico, além de buscar proporcionar ao ser humano uma existência mais poética, reconhecendo na Literatura, por meio da imaginação literária, uma atuação que perturba, intriga, desconcerta, confronta. 
Nesse sentido, oportuno recordar o teor do ditado romano, segundo o qual Direito é feito por e para pessoas. Ele deve se prestar, da maneira mais abrangente possível, a atender as necessidades, os conflitos e os problemas da vida humana em seus aspectos social, cultural, político e filosófico. Portanto, a complexidade da vida humana apresenta novos desafios ao Direito e exige reflexão, novas posturas e, assim, novos olhares, e aí reside a principal contribuição dos ângulos analisados sob os olhares palomarianos.

Como dito anteriormente, os ângulos palomarianos apresentam-se sob as diferentes lentes com que se pode exercer a atividade do olhar, do perceber, do posicionar-se em distintos ângulos para buscar uma visão do todo, embora a compreensão da impossibilidade de apreensão do todo, de esgotar todas as suas possibilidades. Tais ângulos demonstram que são muitas as situações, as teorias, as possibilidades. Não há como precisar todas as situações, nem como apontar alguma resposta como a mais correta ou mais completa, na medida em que é impossível encerrar tão ricas possibilidades com o ranço ainda predominantemente cartesiano do conhecimento humano. Nesse sentido, cabe trazer a instigante pergunta formulada por Ost, bem como sua interessante resposta: "De que forma a Literatura fornece respostas? Eu diria: sempre de maneira indireta, oblíqua, imprevista" (2017, p. 264).

Assim como Palomar, muitas vezes os seres humanos tentam conceituar, explicar, responder questões complexas que podem não ter conceitos, explicações, respostas. Talvez a razão de sua existência e importância seja explicar tudo e não explicar nada, responder tudo e não responder nada, num dos mais instigantes paradoxos da chamada pósmodernidade. Enquanto isso, outros não buscam respostas, explicações, conceitos, simplesmente porque seus condicionantes pessoais e culturais assim não lhes permitem... preferem a comodidade do senso comum, já que trilhar o caminho conhecido é menos trabalhoso que percorrer caminhos inóspitos, desbravar o desconhecido, aventurar-se por areias movediças.

Por isso, é preciso estar preparado para inverter os papéis e colocar-se no local do diferente para melhor percebê-lo e compreendê-lo, uma vez que os pontos de igualdade e de diferença interessam para a compreensão de si mesmo e do mundo, como revelam os ângulos palomarianos ora visitados, sem um ponto final em suas possibilidades. Afinal, o Direito nada mais é do 
que Palomar, porque precisa ser visto, percebido e concebido sempre in fieri, nunca pronto e acabado, reconhecendo-se sua necessária e indissolúvel vinculação com a Literatura, reconhecendo-se que a Literatura instaura experiências em quem lê, de modo a exercer diferentes tipos de impactos, porque é problematizadora em diferentes níveis e de diferentes situações. A Literatura é problematizadora como Palomar, como o Direito, como a vida.

\section{REFERÊNCIAS}

BENJAMIN, Walter. O narrador: considerações sobre a obra de Nikolai Leskov. In: BENJAMIN, Walter. Magia e técnica, arte e política: ensaios sobre literatura e história da cultura; v. 1. São Paulo: Brasiliense, 1994. p. 197-221.

BERND, Zilá. Viajante. In: BERND, Zilá (Org.). Dicionário de figuras e mitos literários das Américas. Porto Alegre: Tomo Editorial; Editora da Universidade, 2007. p. 670-679.

CALVINO, Ítalo. Palomar. Trad. de Ivo Barroso. São Paulo: Companhia das Letras, 1994.

CALVINO, Ítalo. Seis propostas para o próximo milênio. São Paulo: Companhia das Letras, 1990.

DUARTE, Isabel Cristina Brettas; MADERS, Angelita Maria. O direito e a literatura cruzando os caminhos da justiça poética: um caminho sem fim? Anais do IV CIDIL, v. 1, p. 162-181, 2016. Disponível em: $<$ http://rdl.org.br/seer/index.php/anacidil/article/view/103/296 $>$. Acesso em: 8 set. 2016.

DWORKIN, Ronald. Uma questão de princípio. São Paulo: Martins Fontes, 2000.

EAGLETON, Terry. Teoria da literatura: uma introdução. Trad. de Waltensir Dutra. São Paulo: Martins Fontes, 2006.

FOUCAULT, Michel. Microfísica do poder. Rio de Janeiro, Graal, 1992.

GALEANO, Eduardo H. De pernas para o ar: a escola do mundo ao avesso. Trad. de Sergio Faraco; com gravuras de José Guadalupe Posada. Porto Alegre: L\&:PM, 2015.

GUERRA FILHO, Willis Santiago; CANTARINI, Paola. Teoria poética do direito. Rio de Janeiro: Lumen Juris, 2014.

HELLMANN, Risolete Maria. O olhar pós-moderno: uma leitura de Palomar. Anuário de Literatura, v. 15, n. 1, p. 49-62, 2010. Disponível em: <https://periodicos.ufsc.br/index.php/literatura/article/view/2175-

7917.2010v15n1p49>. Acesso em: 8 set. 2016. doi: 10.5007/21757917.2010v15n1p49 
MATURANA, Humberto. Cognição, ciência e vida cotidiana. Belo Horizonte: UFMG, 2001.

NUSSBAUM, Martha. Justicia poética: la imaginación literária y la vida pública. Trad. de Carlos Gardini. Barcelona: Andrés Bello, 1997.

OHLWEILER, Leonel. Aproximações hermenêuticas entre direito e literatura: a narratividade dos princípios constitucionais da administração pública. In: TRINDADE, André Karam; SCHWARTZ, Germano (Org.). Direito e literatura: o encontro entre Themis e Apolo. Curitiba: Juruá, 2008. p. 174-197.

OLIVEIRA, Rafael Tomaz de; ROSA, Alexandre Morais da. Complexo de MacGyver e os modelos de juiz (episódio 1). ConJur, 2013. Disponível em: $<$ https://www.conjur.com.br/2013-nov-02/diario-classe-complexomacgyver-modelos-juiz-episodio > . Acesso em: 26 dez. 2017.

OST, François. Contar a lei: as fontes do imaginário jurídico. São Leopoldo: Unisinos, 2004.

OST, François. Júpiter, Hércules, Hermes: tres modelos de juez. Academia - Revista sobre Enseñanza del Derecho, n. 8, p. 101-130, 2007. Disponível em:

<http://www.derecho.uba.ar/publicaciones/rev academia/revistas/o8/jup iter-hercules-hermes-tres-modelos-de-juez.pdf > . Acesso em: 23 dez. 2017.

OST, François. Direito e literatura: os dois lados do espelho. Anamorphosis - Revista Internacional de Direito e Literatura, v. 3, n. 1, p. 249-264, jan./jun. 2017. doi:10.21119/anamps.31.249-264

PELIZZOLI, Marcelo (Org.). Bioética como paradigma: por um novo modelo biomédico e biotecnológico. Petrópolis: Vozes, 2007.

REMÉDIOS, Maria Luíza Rítzel. O empreendimento autobiográfico. In: ZILBERMAN, Regina et al. As pedras e o arco: fontes primárias, teoria e história da Literatura. Belo Horizonte, EdUFMG, 2004. p. 277-342.

SBIZERA, José Alexandre Ricciardi. Arte e direito: o lugar da Literatura na formação do jurista crítico-sensível. Rio de Janeiro: Lumen Juris, 2015.

SILVA, Ana Isabel Gama. O conceito de Justiça Poética em Martha Nussbaum. Dissertação (Mestrado em Estética e Filosofia da Arte)Faculdade de Letras, Universidade de Lisboa, Lisboa, 2006. Disponível em: <http://revistaphilosophica.weebly.com/2007.html $>$. Acesso em: 8 set. 2016.

SILVA, Henriqueta Alves; MARANGON, Marcio Luis; ROSA, Rudinei da. Introdução. In: SILVA, Henriqueta Alves; MARANGON, Marcio Luis; ROSA, Rudinei da. Caminhos da Educação: realidades e perspectivas. Frederico Westphalen: URI, 2009

STEIN, Ernildo. Aproximações sobre hermenêutica. Porto Alegre: Edipucrs, 1996.

STRECK, Lenio Luiz. Verdade e consenso: Constituição, hermenêutica e teorias discursivas. Rio de Janeiro: Lúmen Juris, 2006.

STRECK, Lenio Luiz. Hermenêutica jurídica e $(m)$ crise. Porto Alegre: Livraria do Advogado, 2004. 
STRECK, Lenio Luiz. Hermenêutica (jurídica) e Estado Democrático de Direito: uma análise crítica. In: Anuário do Programa de Pós-graduação em Direito - Mestrado e Doutorado. São Leopoldo: Unisinos, 1999.

WARAT, Luis Alberto. Mitos e teorias na interpretação da lei. Porto Alegre: Síntese, 1979.

Idioma original: Português

Recebido: 18/04/17

Aceito: 22/12/17 